\title{
Research on a Dynamic Master-Slave Cournot Triopoly Game Model with Bounded Rational Rule and Its Control
}

\author{
Hongliang Tu and Xinyu Wang \\ School of Management, China University of Mining and Technology, Xuzhou 221116, China \\ Correspondence should be addressed to Xinyu Wang; wangxinyu@cumt.edu.cn
}

Received 3 December 2015; Accepted 18 February 2016

Academic Editor: Muhammad N. Akram

Copyright (C) 2016 H. Tu and X. Wang. This is an open access article distributed under the Creative Commons Attribution License, which permits unrestricted use, distribution, and reproduction in any medium, provided the original work is properly cited.

The oligopoly market is modelled by a new dynamic master-slave Cournot triopoly game model with bounded rational rule. The local stabile conditions and the stable region are got by the dynamical systems bifurcation theory. The dynamics characteristics of the system with the changes of the adjustment speed parameters are analyzed by means of bifurcation diagram, largest Lyapunov exponents, phase portrait, and sensitive dependence on initial conditions. Furthermore, the parameters adjustment method is used to control the complex dynamical behaviors of the systems. The derived results have some important theoretical and practical meanings for the oligopoly market.

\section{Introduction}

The structure of a market is dominated by a few firms, which is called oligopoly. Cournot triopoly game has three players who take output as the decision variable in an oligopoly market. Triopoly market structure is a common market structure in the real economic system.

Research on the dynamic nonlinear economic systems is a very hot topic in the economic field. Many researchers have made a lot of research on this aspect and have derived abundant achievements. In recent years, many dynamic Cournot game models were introduced in the related references, and the stability and complex dynamics characteristics were got, such as bifurcation, chaos and its control, and other complex phenomena.

The dynamic Cournot game models were discussed in the following references. Fanti et al. [1] analyzed the dynamics of a nonlinear Cournot duopoly with managerial delegation. Ma and Ji [2] considered a Cournot model in electric power triopoly with nonlinear inverse demand function and cost functions. $\mathrm{Ma}$ and $\mathrm{Tu}$ [3] studied the complexity of a duopoly game in the electricity market under the background of development of new energy with delayed bounded rationality. Wu and $\mathrm{Ma}$ [4] established and investigated the complexity of a multiproduct Cournot duopoly game with managerial delegation. Matsumoto and Nonaka [5] researched the complexity of a Cournot model with linear cost functions and complementary goods. Tramontana [6] and Tramontana and Elsadany [7] found two routes which were the flip bifurcations and the Neimark-Sacker bifurcation to chaos in a duopoly and triopoly game model with isoelastic demand function and heterogeneous players, respectively. Yao et al. [8] analyzed a dynamic triopoly game model with isoelastic demand function and fully heterogeneous players: bounded rational, adaptive, and naive. Yassen and Agiza [9] studied a Cournot duopoly game and the model with delayed rationality and found that delay structure was in favor of enlarging the stable region.

Nonlinear dynamic Bertrand game models were also researched in the following references, in which players took price as the decision variable. Chen et al. [10] applied the Bertrand triopoly model with linear demand functions to study the competition in Chinese telecommunications market. Guo and Ma [11] studied the dynamics characteristics of nonlinear dynamic system in the closed-loop supply chain. Li et al. [12] analyzed dynamics in a dual-channel energy supply chain model with heterogeneous retailers. Ma and Guo [13] researched the complex dynamics characteristics and RLS estimation's influence on a price and service game. Ma and Li [14] constructed dynamic Bertrand-Stackelberg pricing 
models in a risk-averse supply chain which followed these strategies: Bertrand game between the two manufacturers and Stackelberg game between the manufacturer and the retailer. Sun and Ma [15] studied and simulated dynamics of Bertrand triopoly game with team players. Sun and Ma [16] introduce a triopoly Bertrand game model and applied it in Chinese cold rolled steel market.

Dynamic Cournot-Bertrand duopoly mixed game models were studied in the following references, in which one player chooses output and the other player chooses price as decision variable. Naimzada and Tramontana [17] considered a product differentiation Cournot-Bertrand duopoly model with linear demand and cost functions and studied the stability and dynamics properties of this kind of mixed oligopoly game. $\mathrm{Ma}$ and $\mathrm{Pu}$ [18] researched the complex characteristics on a Cournot-Bertrand duopoly model with heterogeneous goods, and the chaos control of the system was used by the state feedback method and the parameter variation control method. Wang and Ma [19] analyzed the complexity on a Cournot-Bertrand duopoly game model with limited information and discussed the influences of the parameters on the system features from the view of economics.

In these nonlinear dynamic system models, the price is determined by either the respective demand or the total demand in the oligopoly market, in which the price is directly or indirectly determined by all the oligopoly enterprises. In this paper, a special price determined mechanism will be considered in the triopoly oligopoly market, in which the market price is only decided by the two mater firms according to their inverse demand, and the slave firm just accepts it. This price determined mechanism exists in the real world because of the relationship between the enterprises and the cost of the determining price.

The paper is organized as follows. In Section 2, we describe a dynamic master-slave Cournot triopoly game model with bounded rational rule. Then, the fixed points and the local stability of the system are discussed. The complex behaviors are illustrated by numerical simulations. In Section 3, the chaotic systems sensitively dependent on initial conditions are confirmed. In Section 4, the system in a chaotic state is controlled by the parameters adjustment method. Finally, the derived results are summarized:

(1) A new dynamic master-slave Cournot triopoly game model with bounded rational rule is established, in which the market price is only decided by the two mater firms according to their inverse demand, but the slave firm just accepts it.

(2) The market is in a stable state if the output adjustment speed parameters are in the stable region. It is easy for the market to fall into high periods and chaos while the output adjustment speed parameters are out of the stable region. The output adjustment speed parameters of the mater enterprise can affect the stability of all the three firms, but the output adjustment speed parameter of the slave enterprise cannot affect the stability of the two mater enterprises.
(3) The parameters adjustment method is provided for the government to regulate the volatile market and make sure that the chaotic economic system can be restabilized at Nash equilibrium point.

\section{The Bounded Rational Rule Model}

In order to establish the model, we make the assumptions as follows:

(1) It is assumed that there are three firms $X_{1}, X_{2}$, and $X_{3}$ in the oligopoly market, in which firms $X_{1}, X_{2}$ are in the mater position and firm $X_{3}$ is in the slave position. The three firms produce the homogeneous commodity, and there is no price competition between them.

(2) The commodity price is only determined by the mater firms $X_{1}, X_{2}$ based on their inverse demand, and the slave firm $X_{3}$ only accepts it.

(3) The firm $X_{i}(i=1,2,3)$ seeks the maximum of profit, and suppose the $t$-output is $q_{i}(t)(i=1,2,3)$. The firm $X_{i}(i=1,2,3)$ has a quadratic form cost function.

Assume the market price is determined by the inverse demand function based on the total output of the mater firms $X_{1}$ and $X_{2}$, and the inverse demand function has the following linear form:

$$
p(t)=a-b\left(q_{1}(t)+q_{2}(t)\right),
$$

and the cost function of the firm is

$$
C_{i}(t)=c_{i} q_{i}^{2}(t) \quad(i=1,2,3),
$$

where $a, b$ are positive constants and $c_{i}(i=1,2,3)$ is the positive variable cost parameter.

So, we can get the profit of the firm $X_{i}(i=1,2,3)$ :

$$
\begin{array}{r}
\pi_{i}(t)=\left(a-b\left(q_{1}(t)+q_{2}(t)\right)\right) q_{i}(t)-c_{i} q_{i}^{2}(t) \\
(i=1,2,3) .
\end{array}
$$

Then, we suppose that the firm $X_{i}(i=1,2,3)$ takes bounded rational rule where the firm makes the next-period output decision based on its current output and marginal profit. The dynamic adjustment mechanism can be written as

$$
q_{i}(t+1)=q_{i}(t)+\alpha_{i} q_{i}(t) \frac{\partial \pi_{i}(t)}{\partial q_{i}(t)} \quad(i=1,2,3),
$$

where $\alpha_{i}(i=1,2,3)$ is a positive parameter which represents the output speed adjustment of the firm $X_{i}(i=1,2,3)$ and $\partial \pi_{i}(t) / \partial q_{i}(t)(i=1,2,3)$ is the marginal profit of the $i$ th firm.

Combining (3) and (4), a new dynamic master-slave Cournot triopoly game model with bounded rational rule is 
described by a 3-dimensional dynamic system in the following form:

$$
\begin{aligned}
& q_{1}(t+1) \\
&= q_{1}(t)+\alpha_{1} q_{1}(t)\left[a-2\left(b+c_{1}\right) q_{1}(t)-b q_{2}(t)\right], \\
& q_{2}(t+1) \\
&= q_{2}(t)+\alpha_{2} q_{2}(t)\left[a-2\left(b+c_{2}\right) q_{1}(t)-b q_{1}(t)\right], \\
& q_{3}(t+1) \\
&=q_{3}(t) \\
& \quad+\alpha_{3} q_{3}(t)\left[a-b\left(q_{1}(t)+q_{2}(t)\right)-2 c_{3} q_{3}(t)\right] .
\end{aligned}
$$

2.1. The Fixed Points and Local Stability Analysis. In system (5), the output adjustment speed parameter $\alpha_{i}(i=1,2)$ is taken as the bifurcation parameter, and the other parameters are constants.

We can get the fixed points of system (5) by solving the following algebraic equations:

$$
\begin{aligned}
q_{1}\left[a-2\left(b+c_{1}\right) q_{1}-b q_{2}\right] & =0, \\
q_{2}\left[a-2\left(b+c_{2}\right) q_{1}-b q_{1}\right] & =0, \\
q_{3}\left[a-b\left(q_{1}+q_{2}\right)-2 c_{3} q_{3}\right] & =0 .
\end{aligned}
$$

Equations (6) have seven meaningful fixed points: $E_{1}=$ $\left(0,0, a / 2 c_{3}\right), E_{2}=\left(0, a / 2\left(b+c_{2}\right), 0\right), E_{3}=\left(a / 2\left(b+c_{1}\right), 0,0\right)$, $E_{4}=\left(0, a / 2\left(b+c_{2}\right), a / 2 c_{3}-a b / 4\left(b+c_{2}\right) c_{3}\right), E_{5}=(a / 2(b+$ $\left.\left.c_{1}\right), 0, a / 2 c_{3}-a b / 4\left(b+c_{1}\right) c_{3}\right), E_{6}=\left(\left(2 a\left(b+c_{2}\right)-a b\right) /(4(b+\right.$ $\left.\left.\left.c_{1}\right)\left(b+c_{2}\right)-b^{2}\right),\left(2 a\left(b+c_{1}\right)-a b\right) /\left(4\left(b+c_{1}\right)\left(b+c_{2}\right)-b^{2}\right), 0\right)$, and $E_{7}=\left(q_{1}^{*}, q_{2}^{*}, q_{3}^{*}\right)=\left(\left(2 a\left(b+c_{2}\right)-a b\right) /\left(4\left(b+c_{1}\right)\left(b+c_{2}\right)-\right.\right.$ $\left.\left.b^{2}\right),\left(2 a\left(b+c_{1}\right)-a b\right) /\left(4\left(b+c_{1}\right)\left(b+c_{2}\right)-b^{2}\right),\left(a / 2 c_{3}\right)\left(q_{1}^{*}+q_{2}^{*}\right)\right)$. $E_{i}(i=1,2,3,4,5,6)$ is boundary equilibria which means that at least one firm is out of the market. Here, we only consider the stability of the Nash equilibrium point $E_{7}$.

In order to investigate the local stability of the Nash equilibrium point $E_{7}$, we can get the Jacobian matrix of system (5) at $E_{7}$ :

$$
\begin{aligned}
& J \\
& =\left(\begin{array}{ccc}
1-2 \alpha_{1}\left(b+c_{1}\right) q_{1}^{*} & -\alpha_{1} b q_{1}^{*} & 0 \\
-\alpha_{2} b q_{2}^{*} & 1-2 \alpha_{1}\left(b+c_{2}\right) q_{2}^{*} & 0 \\
-\alpha_{3} b q_{3}^{*} & -\alpha_{3} b q_{3}^{*} & 1-2 \alpha_{3} c_{3} q_{3}^{*}
\end{array}\right) .
\end{aligned}
$$
(5) at $E_{7}$ :

Then, we can get the characteristic polynomial of system

$$
f(\lambda)=\lambda^{3}+A_{2} \lambda^{2}+A_{1} \lambda+A_{0},
$$

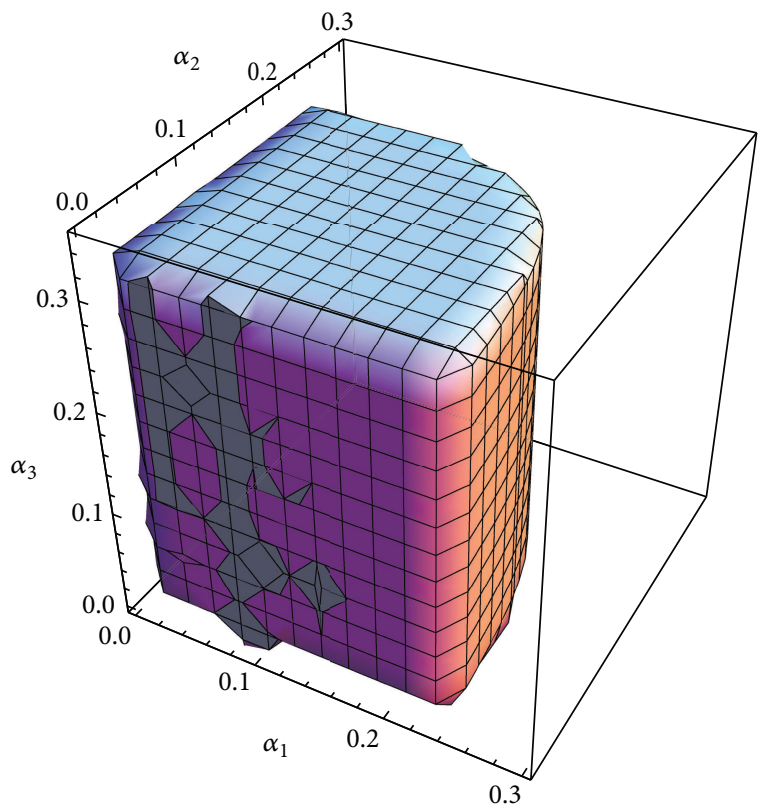

FIgURE 1: The 3-dimensional stable region of system (5).

where

$$
\begin{aligned}
A_{2} & =-\left(3-2 \alpha_{1}\left(b+c_{1}\right) q_{1}^{*}-2 \alpha_{2}\left(b+c_{2}\right) q_{2}^{*}\right. \\
& \left.-2 \alpha_{3} c_{3} q_{3}^{*}\right), \\
A_{1} & =\left[2-2 \alpha_{1}\left(b+c_{1}\right) q_{1}^{*}-2 \alpha_{2}\left(b+c_{2}\right) q_{2}^{*}\right](1 \\
& \left.-2 \alpha_{3} c_{3} q_{3}^{*}\right)+\left[1-2 \alpha_{1}\left(b+c_{1}\right) q_{1}^{*}\right][1 \\
& \left.-2 \alpha_{2}\left(b+c_{2}\right) q_{2}^{*}\right]-\alpha_{1} \alpha_{2} b^{2} q_{1}^{*} q_{2}^{*}, \\
A_{0} & =-\left[\left(1-2 \alpha_{1}\left(b+c_{1}\right) q_{1}^{*}\right)\left(1-2 \alpha_{2}\left(b+c_{2}\right) q_{2}^{*}\right)\right. \\
& \left.-\alpha_{1} \alpha_{2} b^{2} q_{1}^{*} q_{2}^{*}\right]\left(1-2 \alpha_{3} c_{3} q_{3}^{*}\right) .
\end{aligned}
$$

According to the Jury test, the Nash equilibrium $E_{7}$ is locally stable if the following inequality conditions are satisfied:

(i) $f(1)=A_{2}+A_{1}+A_{0}+1=2 \alpha_{1} \alpha_{2} \alpha_{3} c_{3}\left[3 b^{2}+4 b\left(c_{1}+\right.\right.$ $\left.\left.c_{2}\right)+4 c_{1} c_{2}\right] q_{1}^{*} q_{2}^{*} q_{3}^{*}>0$

(ii) $-f(-1)=-A_{2}+A_{1}-A_{0}+1=\left(2-2 \alpha_{3} c_{3} q_{3}^{*}\right)[4-$ $4 \alpha_{1}\left(b+c_{1}\right) q_{1}^{*}-4 \alpha_{2}\left(b+c_{2}\right) q_{2}^{*}+4 \alpha_{1} \alpha_{2}\left(b+c_{1}\right)\left(b+c_{2}\right) q_{1}^{*} q_{2}^{*}-$ $\left.\alpha_{1} \alpha_{2} b^{2} q_{1}^{*} q_{2}^{*}\right]>0$;

(iii) $A_{0}^{2}=\left[\left(1-2 \alpha_{1}\left(b+c_{1}\right) q_{1}^{*}\right)\left(1-2 \alpha_{2}\left(b+c_{2}\right) q_{2}^{*}\right)-\right.$ $\left.\alpha_{1} \alpha_{2} b^{2} q_{1}^{*} q_{2}^{*}\right]^{2}\left(1-2 \alpha_{3} c_{3} q_{3}^{*}\right)^{2}<1$

(iv) $\left(1-A_{0}^{2}\right)^{2}-\left(A_{1}-A_{2} A_{0}\right)^{2}>0$.

In order to show the stability region of the model, the constant parameters are given: $a=10, b=0.62, c_{1}=$ $0.58, c_{2}=0.65$, and $c_{3}=0.71$. Then, we can get the Nash equilibrium $E_{4}=(3.3615,3.1165,4.2138)$.

By solving the above equations, the local stable region of the Nash equilibrium point with positive $\left(\alpha_{1}, \alpha_{2}, \alpha_{3}\right)$ in the 3 -dimensional body is shown in Figure 1. Furthermore, the local stable regions of the Nash equilibrium point in the phase 


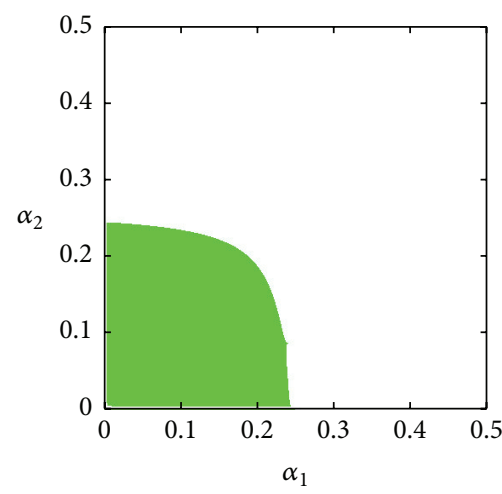

(a)

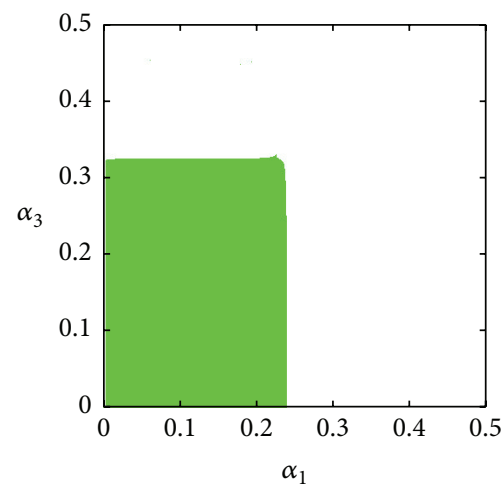

(b)

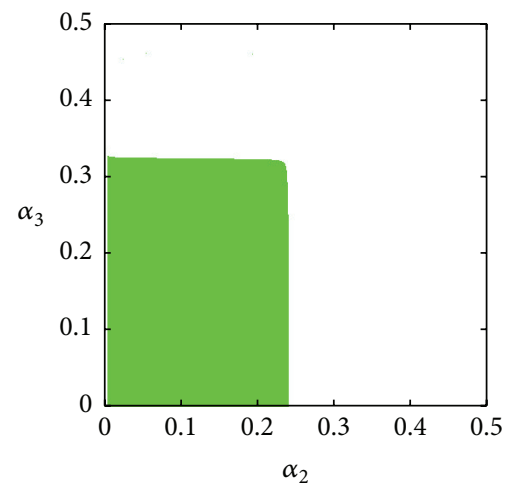

(c)

Figure 2: The stable region of system (5) in the phase plane of (a) $\left(\alpha_{1}, \alpha_{2}\right)$ for $\alpha_{3}=0.037$; (b) $\left(\alpha_{1}, \alpha_{3}\right)$ for $\alpha_{2}=0.046$; (c) $\left(\alpha_{2}, \alpha_{3}\right)$ for $\alpha_{1}=0.052$.

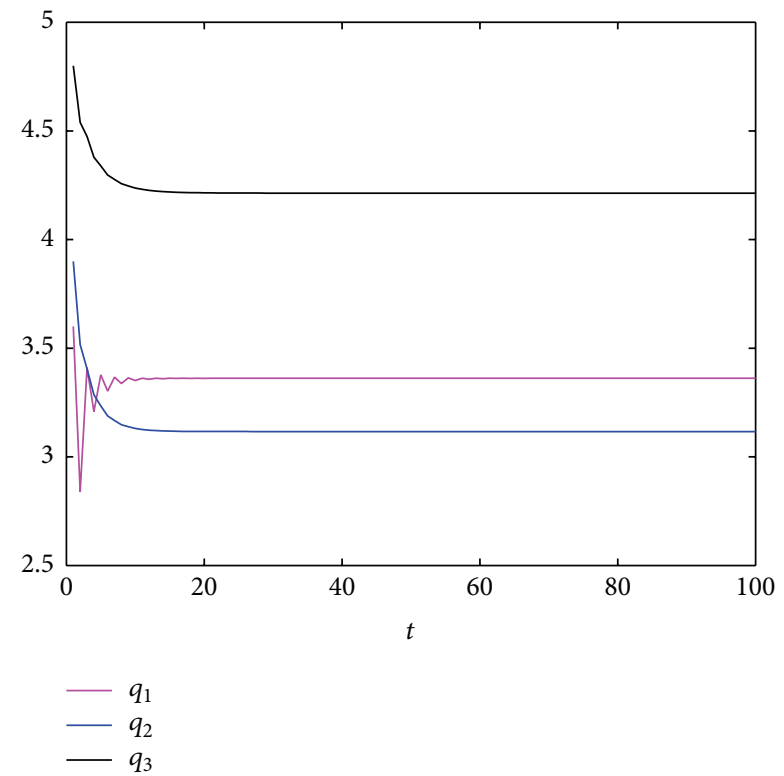

FIgURE 3: The time diagram of the output of system (5) for $\left(\alpha_{1}=0.2\right.$, $\left.\alpha_{2}=0.046, \alpha_{3}=0.037\right)$.

plane are shown in Figure 2. We can see that system (5) is asymptotically stable when the output speed adjustment parameters are small.

All the outputs will finally be stable at Nash equilibrium point after finite games for any given initial datum when the parameters are in the stable region as it is shown in Figure 3.

The firm $X_{i}(i=1,2,3)$ may increase the output adjustment speed parameter to enlarge its output in the hope of getting more profits, which may cause system (5) to be unstable while the output adjustment speed parameter $\alpha_{i}$ $(i=1,2,3)$ is out of the stable region. We show the dynamics features of system (5) by numerical simulations in the next subsection.

2.2. Analysis and Numerical Simulations. The purpose of this part is to display the complex dynamics characteristics of system (5) with the change of the output adjustment speed parameter $\alpha_{i}(i=1,2,3)$ by numerical simulations, such as bifurcation diagrams, largest Lyapunov exponents, strange attractors, and time diagram.

The Nash equilibrium point will become unstable if the dominant firm $X_{1}$ accelerates output adjustment speed $\alpha_{1}$ when $\alpha_{1}$ is out of the stable region. Figure 4 presents bifurcation diagram and the corresponding largest Lyapunov exponents with respect to $\alpha_{1}\left(\alpha_{1} \in(0,0.3714]\right)$ for $\left(\alpha_{2}=\right.$ $\left.0.046, \alpha_{3}=0.037\right)$, respectively. The quantitative characteristics of the dynamic system can be analyzed by the calculation of the largest Lyapunov exponent. The largest Lyapunov exponents are positive when the system is in chaotic state, and they even can differentiate between high order cycles and aperiodic behavior. Moreover, it is better to understand the dynamics properties by comparison with the bifurcation diagram. The output evolutions of the triopoly firms start with equilibrium state, undergo period doubling, and end with chaotic state with the increase of $\alpha_{1}$. We can see that system (5) is stable at the Nash equilibrium point for $0<$ $\alpha_{1}<0.2464$. For $\alpha_{1}>0.2464$, system (5) undergoes doubling period bifurcations to chaos. The strange attractor indicates the inherent regularity of the chaos, which is an important way to portray the chaos. Figure 5 shows two classic chaos attractors of system (5).

Similarly, Figure 6 shows bifurcation diagram and the corresponding largest Lyapunov exponents with respect to $\alpha_{2}$ $\left(\alpha_{2} \in(0,0.3857]\right)$ when $\left(\alpha_{1}=0.052, \alpha_{3}=0.037\right)$. We can see that system (5) is stable at the Nash equilibrium point for $0<\alpha_{2}<0.2450$. When $\alpha_{2}>0.2450$, system (5) loses its stability and undergoes doubling period bifurcations to chaos. Figure 7 shows two typical chaos attractors of system (5).

Likewise, Figure 8 shows bifurcation diagram and the corresponding largest Lyapunov exponents with respect to $\alpha_{3}\left(\alpha_{3} \in(0,0.5071]\right)$ when $\left(\alpha_{1}=0.052, \alpha_{2}=0.046\right)$. The outputs $q_{1}, q_{2}$ are in a stable state for all $\alpha_{3} \in(0,0.5071]$, but the output $q_{3}$ goes into chaos through the period doubling bifurcation for $\alpha_{3}>0.5071$. Figure 9 shows the time diagram of the output of $q_{3}$ for $\left(\alpha_{1}=0.052, \alpha_{2}=0.046, \alpha_{3}=0.47\right)$ when system (5) is in a chaotic state. 


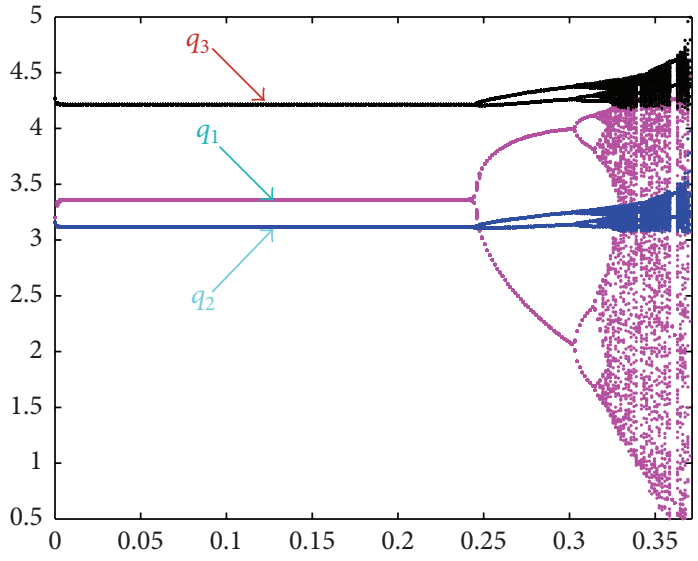

(a)

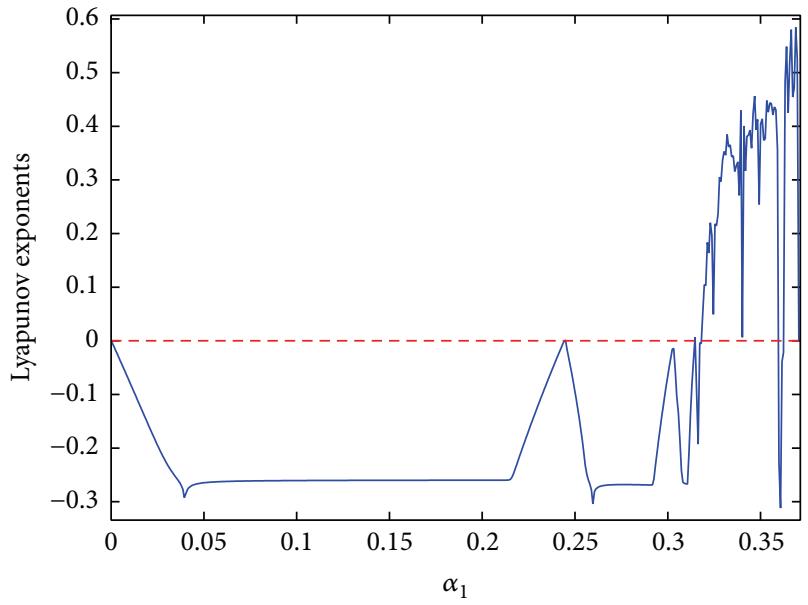

(b)

Figure 4: The bifurcation diagram (a) and the corresponding largest Lyapunov exponents (b) with $\alpha_{1} \in(0,0.3714]$ for $\left(\alpha_{2}=0.046, \alpha_{3}=\right.$ $0.037)$.

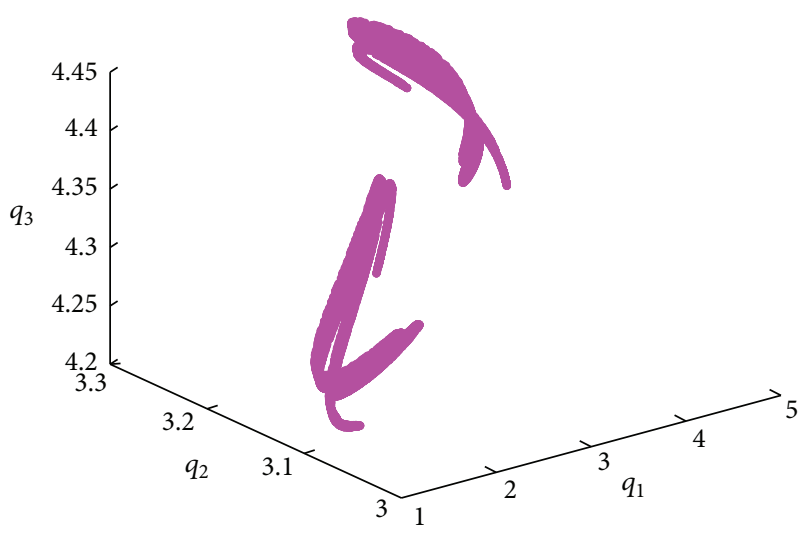

(a)

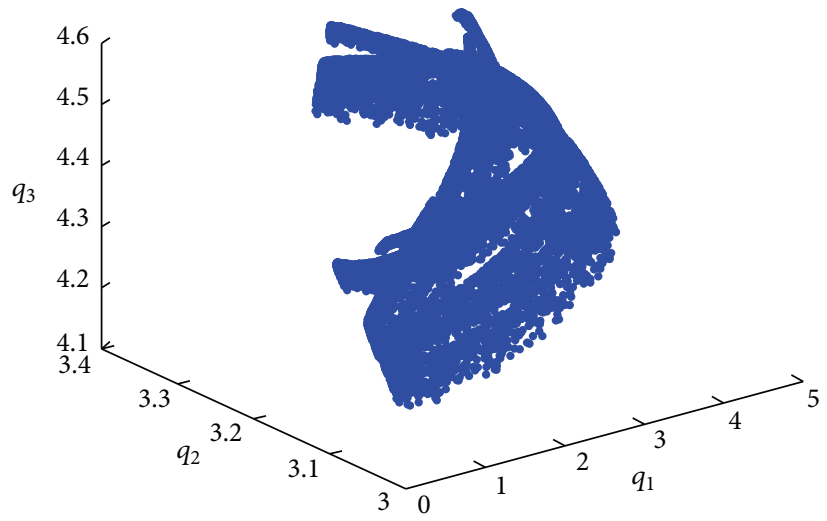

(b)

FIgURE 5: Chaos attractors of system (5) for (a) $\left(\alpha_{1}=0.326, \alpha_{2}=0.046, \alpha_{3}=0.037\right)$ and (b) $\left(\alpha_{1}=0.35, \alpha_{2}=0.046, \alpha_{3}=0.037\right)$.

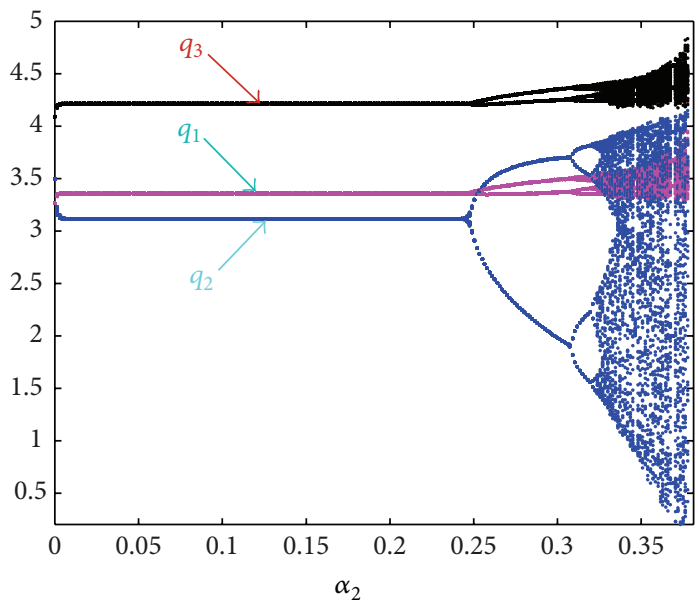

(a)

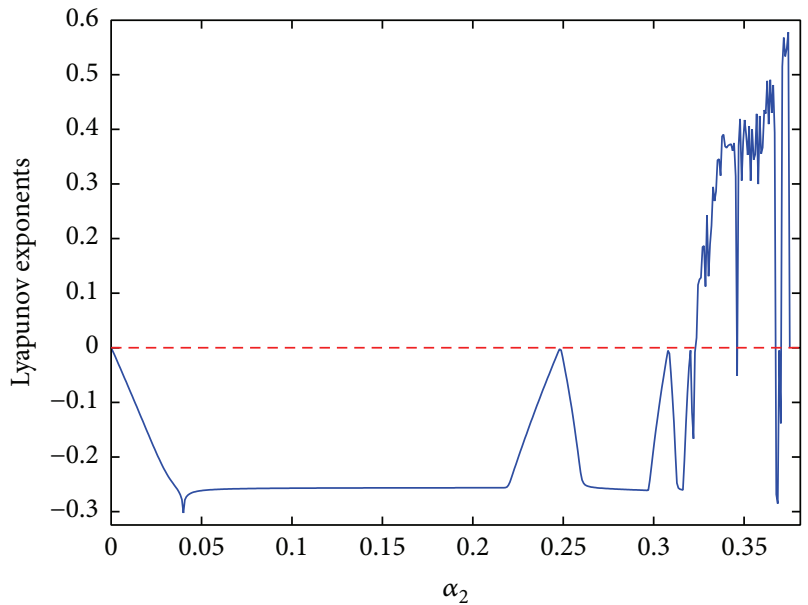

(b)

FIGURE 6: The bifurcation diagram (a) and the corresponding largest Lyapunov exponents (b) with $\alpha_{2} \in(0,0.3811]$ for $\left(\alpha_{1}=0.052, \alpha_{3}=\right.$ 0.037 ). 


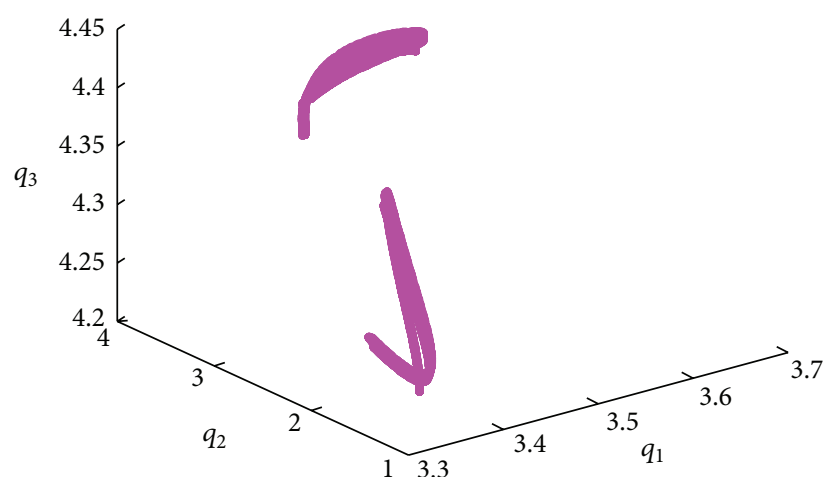

(a)

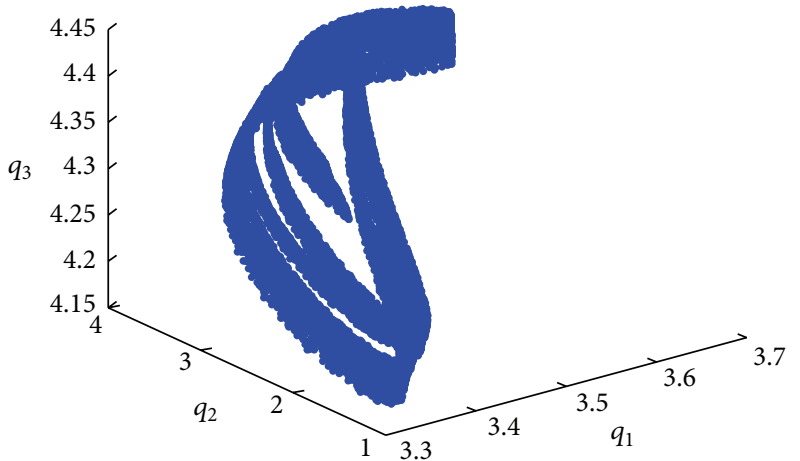

(b)

Figure 7: Chaos attractors of system (5) for (a) $\left(\alpha_{1}=0.052, \alpha_{2}=0.33, \alpha_{3}=0.037\right)$ and (b) $\left(\alpha_{1}=0.052, \alpha_{2}=0.34, \alpha_{3}=0.037\right)$.

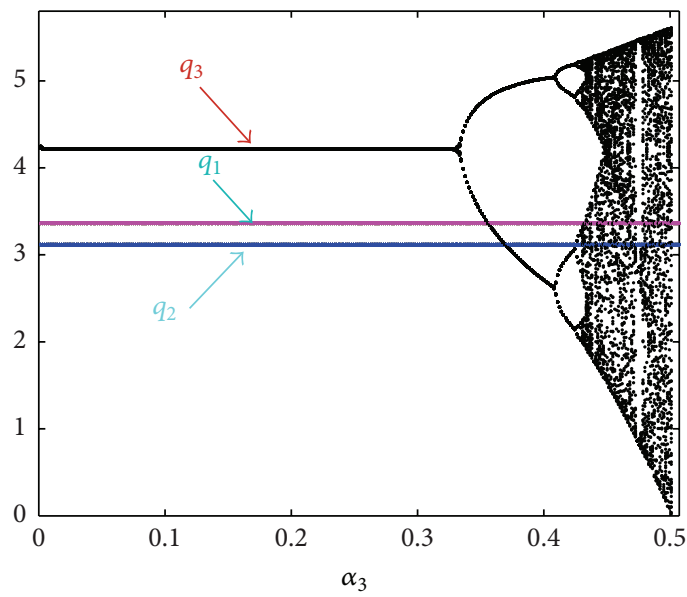

(a)

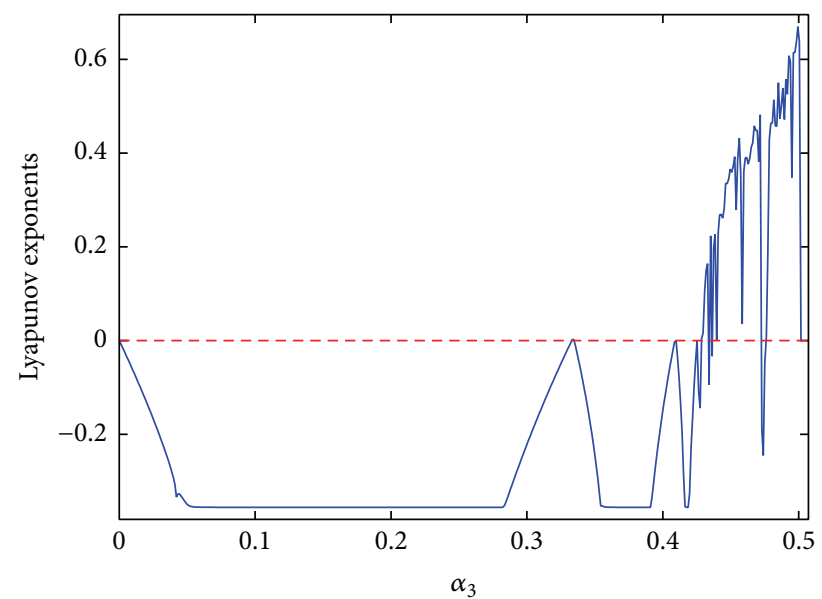

(b)

FiguRE 8: The bifurcation diagram (a) and the corresponding largest Lyapunov exponents (b) with $\alpha_{3} \in(0,0.5071]$ for $\left(\alpha_{1}=0.052, \alpha_{2}=\right.$ $0.046)$.

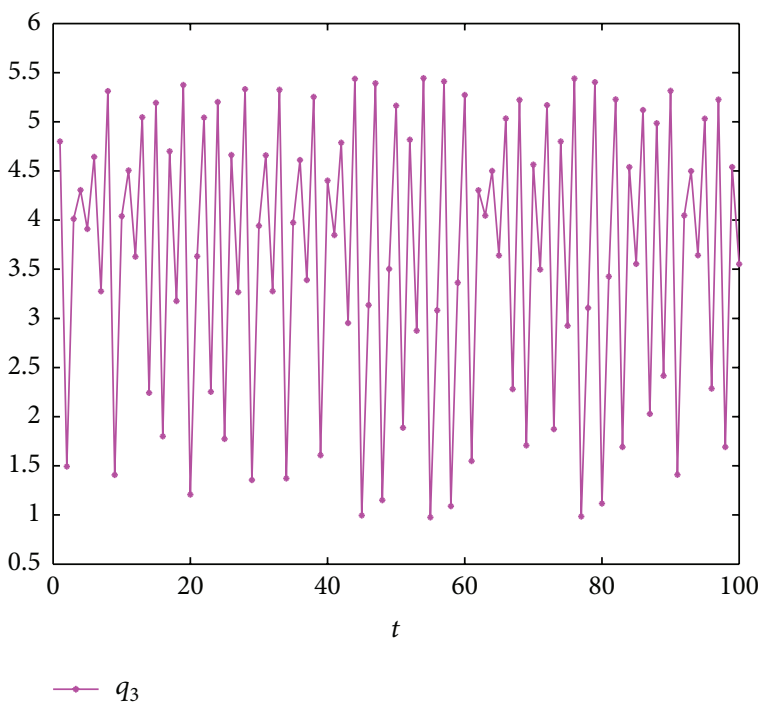

FIgURE 9: The time diagram of the output of $q_{3}$ for $\left(\alpha_{1}=0.052\right.$, $\alpha_{2}=0.046, \alpha_{3}=0.47$ ).
Above all, from the bifurcation diagrams, largest Lyapunov exponents, strange attractors, and time diagram, we can see that the effect of $\alpha_{i}(i=1,2,3)$ on the system is different. Big $\alpha_{i}(i=1,2,3)$ can cause instability, bifurcation, and chaos, but the evolutionary process and the strange attractors are different.

\section{The Sensitive Dependence on Initial Conditions}

One of the most important characteristics of the chaos is sensitive dependence on initial conditions. Figures 10, 11, and 12 show the relationships between output and time to confirm that system (5) sensitively depends on initial datum. Firstly, they are indistinguishable; the difference between them is large when the number of games increases. This demonstrates that a slight difference between initial values can lead to a great difference of the game results. So, every action from the companies can cause great loss. 


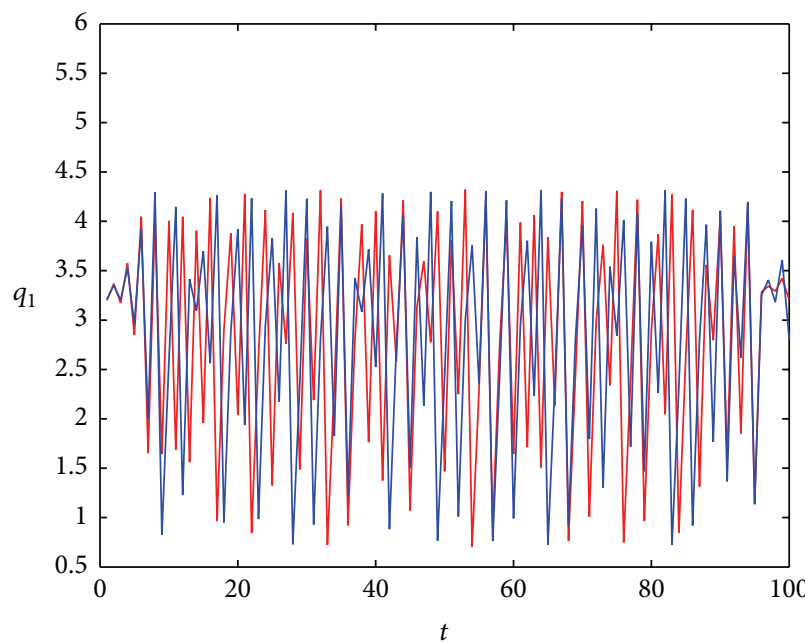

$q_{1_{0}}=3.2$

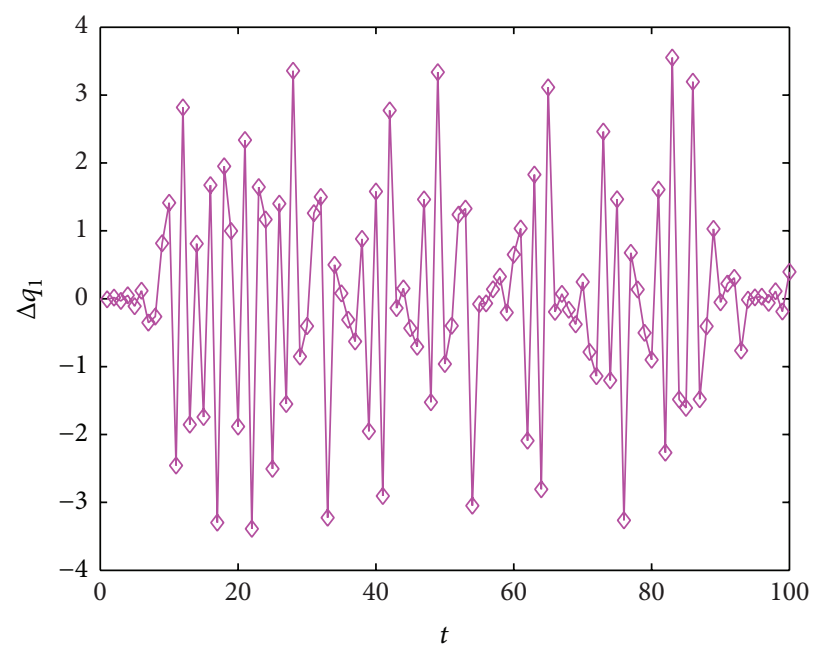

(b)

FIGURE 10: The two orbits (a) and the variety (b) of the $q_{1}$-coordinates of system (5) for initial points are $(3.2,3.5,4.3)$ and $(3.21,3.5,4.3)$ when $\left(\alpha_{1}=0.35, \alpha_{2}=0.046, \alpha_{3}=0.037\right)$, respectively.
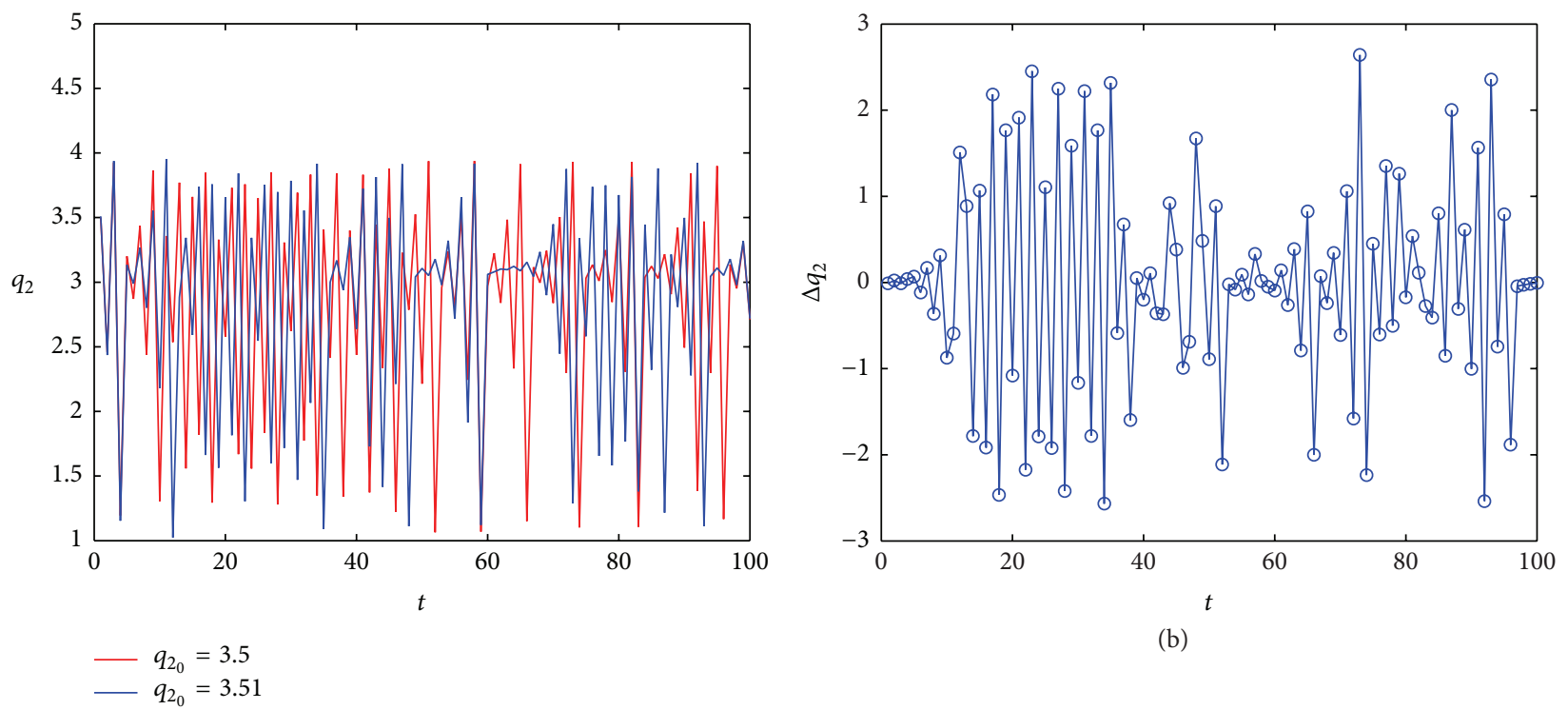

(b)

(a)

Figure 11: The two orbits (a) and the variety (b) of the $q_{1}$-coordinates of system (5) for initial points are $(3.2,3.5,4.3)$ and $(3.2,3.51,4.3)$ when $\left(\alpha_{1}=0.052, \alpha_{2}=0.34, \alpha_{3}=0.037\right)$, respectively.

\section{Chaos Control}

From the above discussion, we know that the system becomes unstable and undergoes doubling bifurcation to chaos. We know that the chaos is harmful to the oligopoly market and the economic system, and it is difficult for the firms to forecast their output and make reasonable decisions. Thus, the government should find some way to eliminate the negative effect of chaos. It is a good ideal for the chaotic dynamic economic system to return to Nash equilibrium point.

Here, the parameters adjustment method is applied to the control of the complex dynamics behaviors of system (5). The controlled system is as follows:

$$
\begin{aligned}
& q_{1}(t+1)=(1-\mu)\left\{q_{1}(t)\right. \\
& \left.\quad+\alpha_{1} q_{1}(t)\left[a-2\left(b+c_{1}\right) q_{1}(t)-b q_{2}(t)\right]\right\}+\mu q_{1}(t),
\end{aligned}
$$




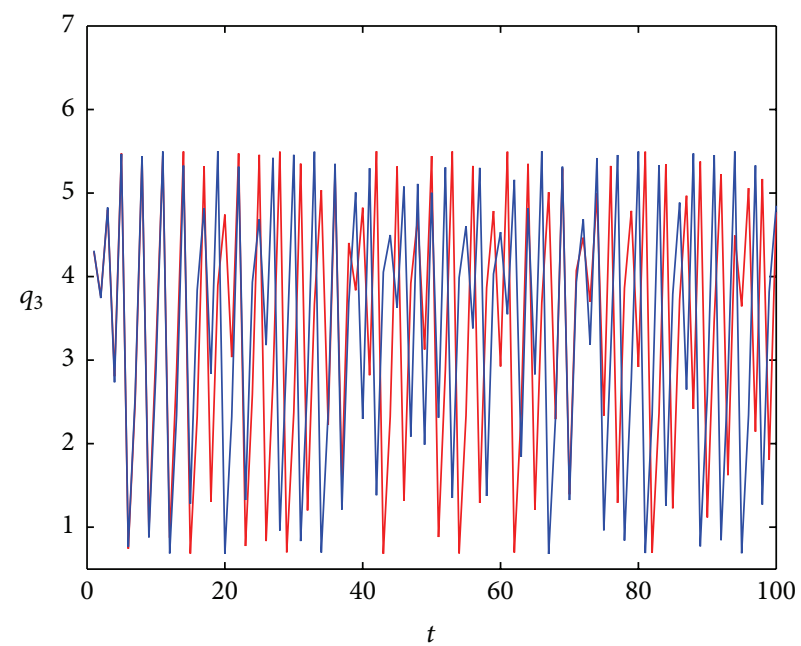

$-q_{3_{0}}=4.3$
$-q_{3_{0}}=4.31$

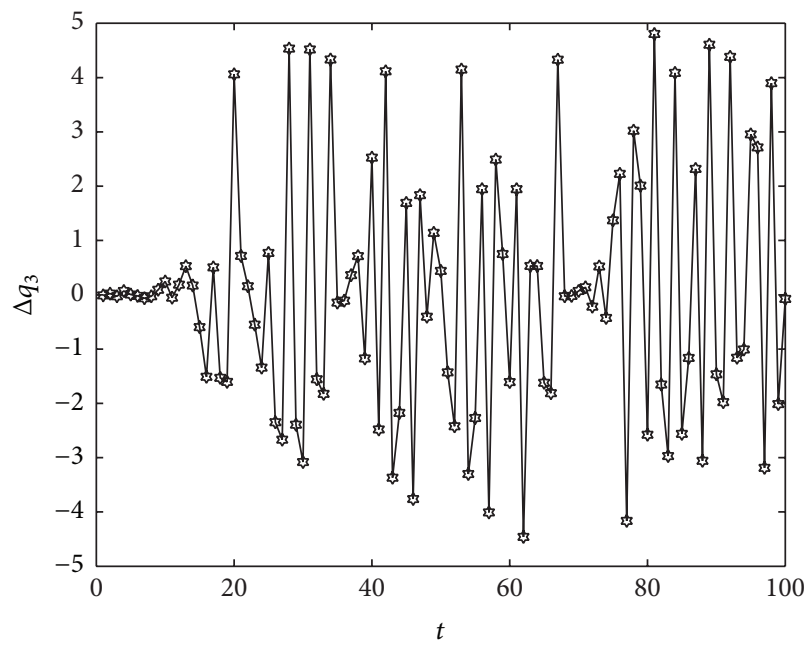

(a)

(b)

FIGURE 12: The two orbits (a) and the variety (b) of the $q_{1}$-coordinates of system (5) for initial points are $(3.2,3.5,4.3)$ and $(3.2,3.5,4.31)$ when $\left(\alpha_{1}=0.052, \alpha_{2}=0.046, \alpha_{3}=0.48\right)$, respectively.

$$
\begin{aligned}
& q_{2}(t+1)=(1-\mu)\left\{q_{2}(t)\right. \\
& \left.\quad+\alpha_{2} q_{2}(t)\left[a-2\left(b+c_{2}\right) q_{1}(t)-b q_{1}(t)\right]\right\}+\mu q_{2}(t), \\
& q_{3}(t+1)=(1-\mu)\left\{q_{3}(t)\right. \\
& \left.\quad+\alpha_{3} q_{3}(t)\left[a-b\left(q_{1}(t)+q_{2}(t)\right)-2 c_{3} q_{3}(t)\right]\right\}
\end{aligned}
$$$$
+\mu q_{3}(t),
$$

where $0<\mu<1$ is the adjustment parameter and the other parameters are the same as above.

We can obtain the Jacobian matrix of system (10) at $E_{3}$ :

$$
J=\left(\begin{array}{ccc}
1-2(1-\mu) \alpha_{1}\left(b+c_{1}\right) q_{1}^{*} & -(1-\mu) \alpha_{1} b q_{1}^{*} & 0 \\
-(1-\mu) \alpha_{2} b q_{2}^{*} & 1-2(1-\mu) \alpha_{1}\left(b+c_{2}\right) q_{2}^{*} & 0 \\
-(1-\mu) \alpha_{3} b q_{3}^{*} & -(1-\mu) \alpha_{3} b q_{3}^{*} & 1-2(1-\mu) \alpha_{3} c_{3} q_{3}^{*}
\end{array}\right)
$$

Then, it is easy to get the characteristic polynomial of system (10) at $E_{3}$ :

$$
f(\lambda)=\lambda^{3}+A_{2} \lambda^{2}+A_{1} \lambda+A_{0}
$$

where

$$
\begin{aligned}
A_{2} & =-\left[3-2(1-\mu) \alpha_{1}\left(b+c_{1}\right) q_{1}^{*}-2(1-\mu)\right. \\
& \left.\cdot \alpha_{1}\left(b+c_{2}\right) q_{2}^{*}-2(1-\mu) \alpha_{3} c_{3} q_{3}^{*}\right], \\
A_{1} & =\left[1-2(1-\mu) \alpha_{1}\left(b+c_{1}\right) q_{1}^{*}\right][1-2(1-\mu) \\
& \left.\cdot \alpha_{1}\left(b+c_{2}\right) q_{2}^{*}\right]+\left[1-2(1-\mu) \alpha_{3} c_{3} q_{3}^{*}\right][2 \\
& \left.-2(1-\mu) \alpha_{1}\left(b+c_{1}\right) q_{1}^{*}-2(1-\mu) \alpha_{2}\left(b+c_{2}\right) q_{2}^{*}\right] \\
& -(1-\mu)^{2} \alpha_{1} \alpha_{2} b^{2} q_{1}^{*} q_{2}^{*},
\end{aligned}
$$

$$
\begin{gathered}
A_{0}=-\left[\left(1-2(1-\mu) \alpha_{1}\left(b+c_{1}\right) q_{1}^{*}\right)\right. \\
\cdot\left(1-2(1-\mu) \alpha_{2}\left(b+c_{2}\right) q_{2}^{*}\right)-(1-\mu)^{2} \\
\left.\cdot \alpha_{1} \alpha_{2} b^{2} q_{1}^{*} q_{2}^{*}\right]\left[1-2(1-\mu) \alpha_{3} c_{3} q_{3}^{*}\right] .
\end{gathered}
$$

According to the Jury test, the necessary and sufficient condition of the local stability of the Nash equilibrium is the following three conditions satisfied:

(i) $f(1)=A_{2}+A_{1}+A_{0}+1=2(1-\mu)^{3} \alpha_{1} \alpha_{2} \alpha_{3} c_{3}\left[3 b^{2}+\right.$ $\left.4 b\left(c_{1}+c_{2}\right)+4 c_{1} c_{2}\right] q_{1}^{*} q_{2}^{*} q_{3}^{*}>0$

(ii) $-f(-1)=-A_{2}+A_{1}-A_{0}+1=\left(2-2(1-\mu) \alpha_{3} c_{3} q_{3}^{*}\right)[4-$ $4(1-\mu) \alpha_{1}\left(b+c_{1}\right) q_{1}^{*}-4(1-\mu) \alpha_{2}\left(b+c_{2}\right) q_{2}^{*}+4(1-$ $\left.\mu)^{2} \alpha_{1} \alpha_{2}\left(b+c_{1}\right)\left(b+c_{2}\right) q_{1}^{*} q_{2}^{*}-(1-\mu)^{2} \alpha_{1} \alpha_{2} b^{2} q_{1}^{*} q_{2}^{*}\right]>0$; 


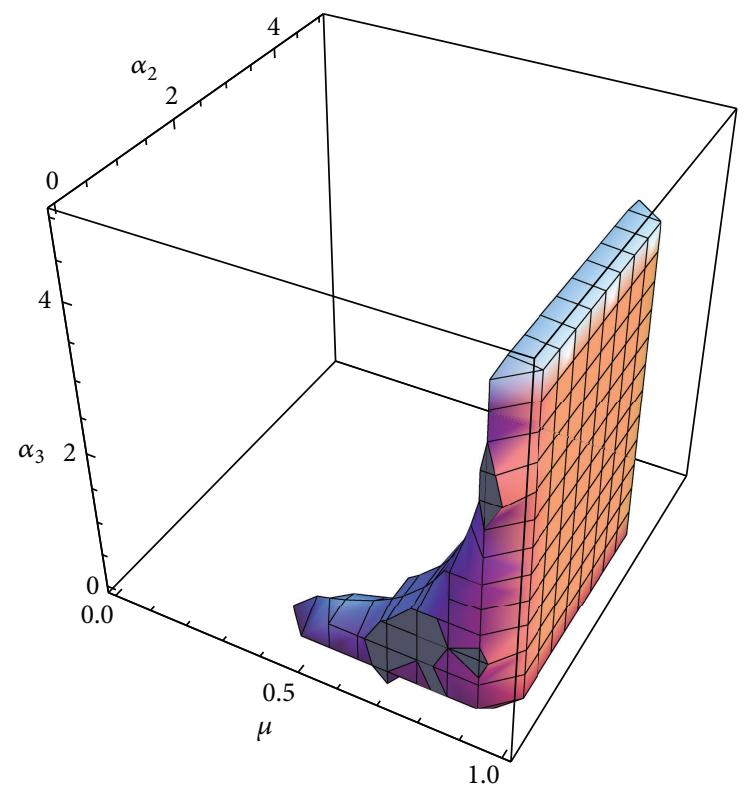

FIgURE 13: The 3-dimensional stable region of system (10) in the phase plane of $\left(\mu, \alpha_{2}, \alpha_{3}\right)$ for $\alpha_{1}=0.35$.

(iii) $A_{0}^{2}=\left[\left(1-2(1-\mu) \alpha_{1}\left(b+c_{1}\right) q_{1}^{*}\right)\left(1-2(1-\mu) \alpha_{2}(b+\right.\right.$ $\left.\left.\left.c_{2}\right) q_{2}^{*}\right)-(1-\mu)^{2} \alpha_{1} \alpha_{2} b^{2} q_{1}^{*} q_{2}^{*}\right]^{2}\left[1-2(1-\mu) \alpha_{3} c_{3} q_{3}^{*}\right]^{2}<1$;

(iv) $\left(1-A_{0}^{2}\right)^{2}-\left(A_{1}-A_{2} A_{0}\right)^{2}>0$.

By solving the above equations, the local 3-dimensional stable regions of the Nash equilibrium point in the phase plane of $\left(\mu, \alpha_{2}, \alpha_{3}\right)$ for $\alpha_{1}=0.35$ are shown in Figure 13 . Figure 14 shows 3-dimensional stable regions of the Nash equilibrium point in the phase plane of $\left(\mu, \alpha_{1}, \alpha_{3}\right)$ for $\alpha_{2}=$ 0.34 . Figure 15 shows 3 -dimensional stable regions of the Nash equilibrium point in the phase plane of $\left(\mu, \alpha_{1}, \alpha_{2}\right)$ for $\alpha_{3}=0.48$.

We know that system (5) loses its stability and falls into chaos with the increase of the output adjustment parameter $\alpha_{i}(i=1,2,3)$. Figure 16 shows the bifurcation diagram and the corresponding largest Lyapunov exponents of system (10) with $\mu \in[0,1]$ for $\left(\alpha_{1}=0.35, \alpha_{2}=0.046, \alpha_{3}=0.037\right)$, and we can see that system (10) goes back to the Nash equilibrium point again when $\mu>0.2959$.

In the same way, Figure 17 shows the bifurcation diagram and the corresponding largest Lyapunov exponents of system (10) with $\mu \in[0,1]$ for $\left(\alpha_{1}=0.052, \alpha_{2}=0.34, \alpha_{3}=\right.$ 0.037 ), and we can see that system (10) goes back to the Nash equilibrium point again when $\mu>0.2653$.

Finally, Figure 18 shows the bifurcation diagram and the corresponding largest Lyapunov exponents of system (10) with $\mu \in[0,1]$ for $\left(\alpha_{1}=0.052, \alpha_{2}=0.046, \alpha_{3}=0.48\right)$, and we can see that system (10) goes back to the Nash equilibrium point again when $\mu>0.3061$.

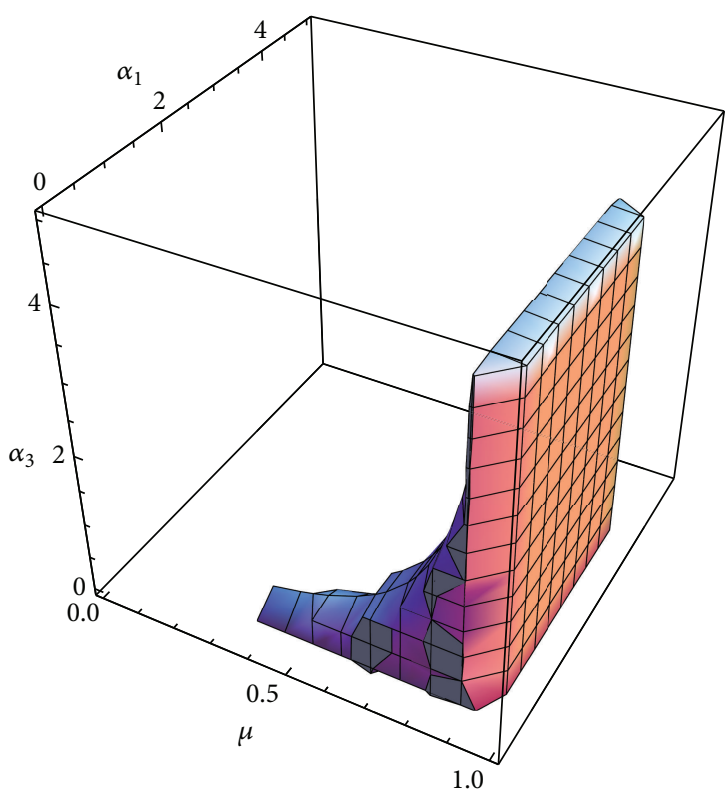

Figure 14: The 3-dimensional stable region of system (10) in the phase plane of $\left(\mu, \alpha_{1}, \alpha_{3}\right)$ for $\alpha_{2}=0.34$.

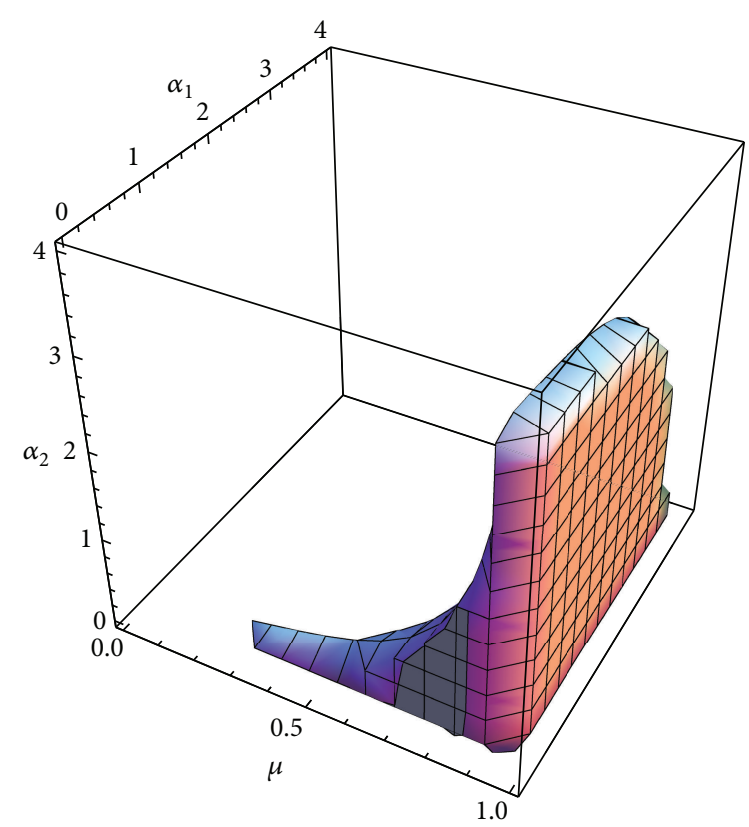

FIGURE 15: The 3-dimensional stable region of system (10) in the phase plane of $\left(\mu, \alpha_{1}, \alpha_{2}\right)$ for $\alpha_{3}=0.48$.

In a word, this reveals that the chaos control of system (5) is a successful parameters adjustment method.

\section{Conclusions}

In this paper, we built up a new dynamic master-slave Cournot triopoly game model with bounded rational players, in which the market price is determined by the two mater 


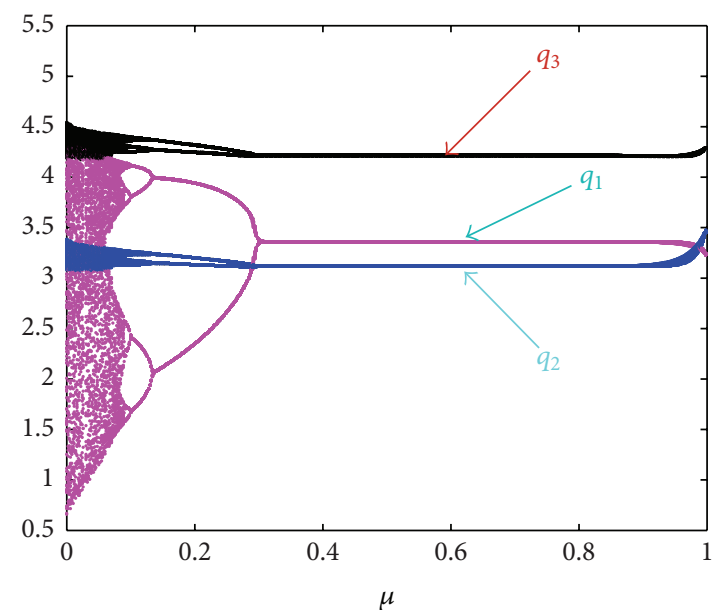

(a)

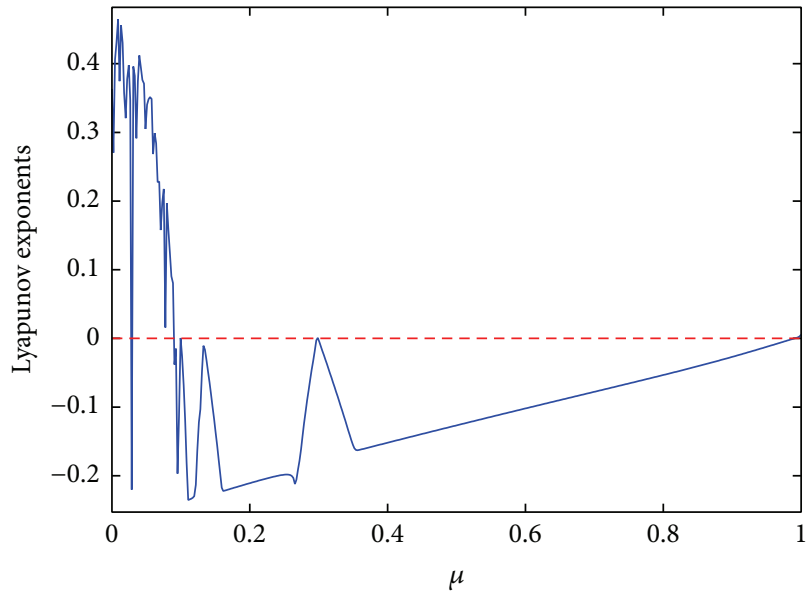

(b)

FIgure 16: The bifurcation diagram (a) and the corresponding largest Lyapunov exponents (b) of system $(10)$ with $\mu \in[0,1]$ for $\left(\alpha_{1}=0.35\right.$, $\left.\alpha_{2}=0.046, \alpha_{3}=0.037\right)$.

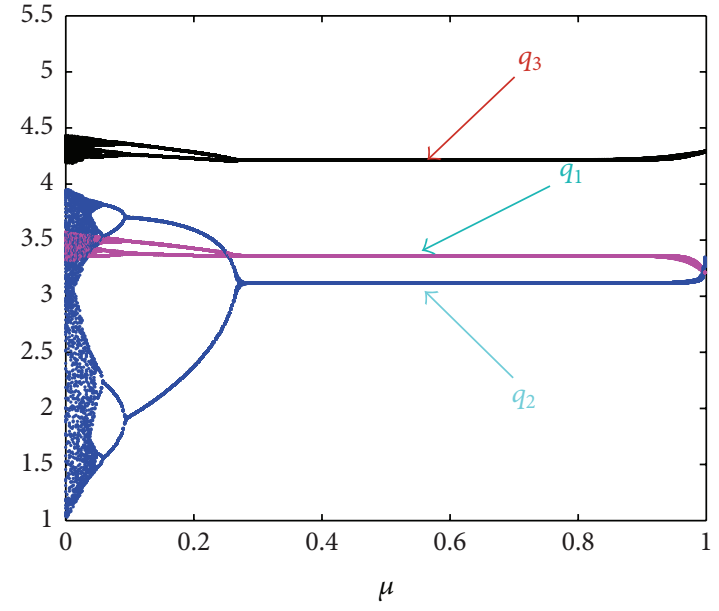

(a)

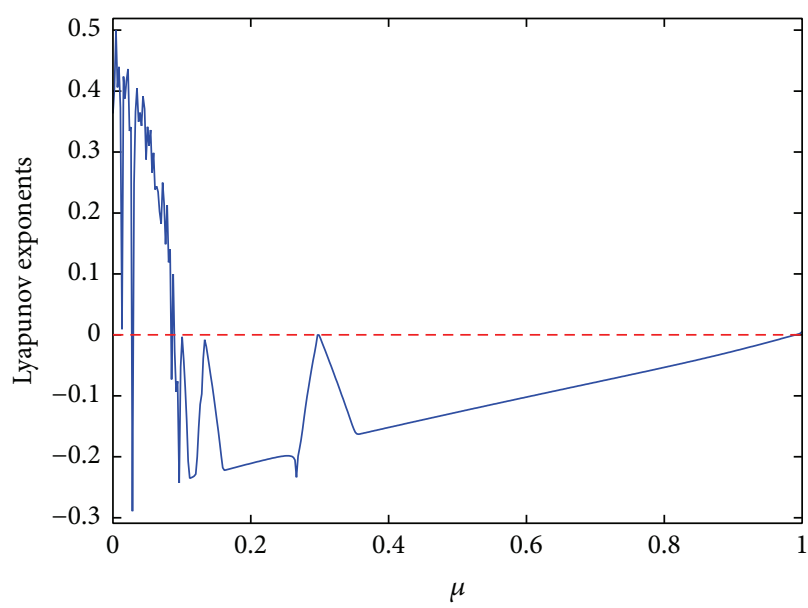

(b)

FIGURE 17: The bifurcation diagram (a) and the corresponding largest Lyapunov exponents (b) of system $(10)$ with $\mu \in[0,1]$ for $\left(\alpha_{1}=0.052\right.$, $\left.\alpha_{2}=0.34, \alpha_{3}=0.037\right)$.

firms based on their inverse demand function. The local stable conditions and region of the Nash equilibrium point are derived.

It is found that the oligopoly market may become unstable and even fall into chaos via doubling period bifurcations with the changes of the output adjustment speed parameters. The complex dynamics properties of the system are shown by numerical simulations, such as bifurcation diagrams, largest Lyapunov exponents, strange attractors, phase portraits, and sensitive dependence on initial conditions.

In order to avoid the negative effect of the chaos, we use the parameters adjustment method to control the chaos. The chaos can be effectively eliminated by the parameters adjustment method, and the chaotic dynamic economic system can be returned to Nash equilibrium point. The derived results have important theoretical and practical meanings for the oligopoly market.

\section{Competing Interests}

The authors declare that there is no conflict of interests regarding the publication of this paper.

\section{Acknowledgments}

The research was supported by the National Natural Science Foundation of China (Grant no. 61273231). It was also supported by the Fundamental Research Funds for the Central 


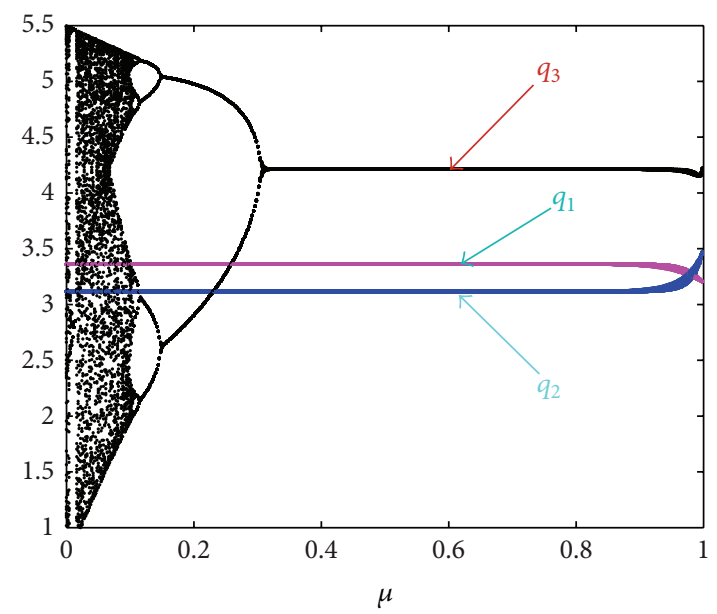

(a)

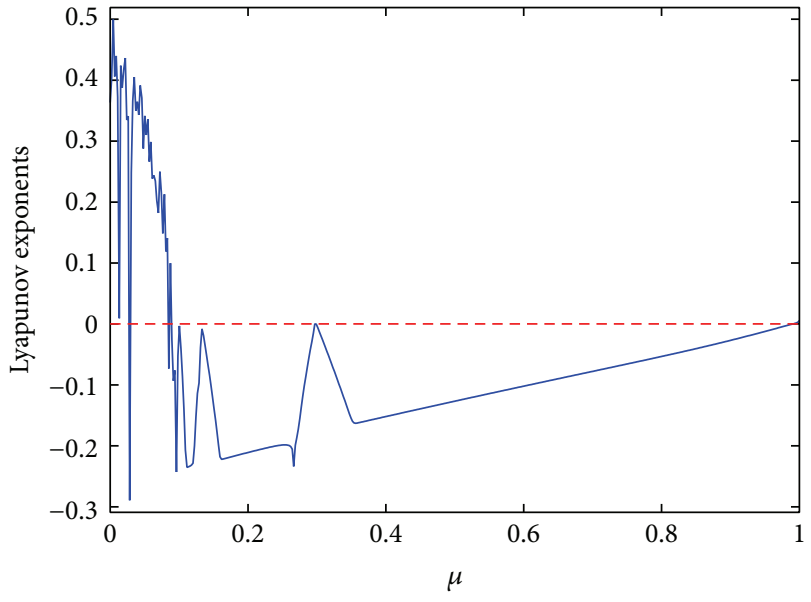

(b)

FIGURE 18: The bifurcation diagram (a) and the corresponding largest Lyapunov exponents (b) of system $(10)$ with $\mu \in[0,1]$ for $\left(\alpha_{1}=0.052\right.$, $\left.\alpha_{2}=0.046, \alpha_{3}=0.48\right)$.

Universities (Grant no. 2014QNB08), Postdoctoral Fund of Jiangsu Province (Grant no. 1401055B), and Department of Education and Social Sciences Project of Jiangsu Province (Grant no. 2014SJD413).

\section{References}

[1] L. Fanti, L. Gori, and M. Sodini, "Nonlinear dynamics in a Cournot duopoly with relative profit delegation," Chaos, Solitons \& Fractals, vol. 45, no. 12, pp. 1469-1478, 2012.

[2] J.-H. Ma and W.-Z. Ji, "Complexity of repeated game model in electric power triopoly," Chaos, Solitons and Fractals, vol. 40, no. 4, pp. 1735-1740, 2009.

[3] J. Ma and H. Tu, "Complexity of a duopoly game in the electricity market with delayed bounded rationality," Discrete Dynamics in Nature and Society, vol. 2012, Article ID 698270, 13 pages, 2012.

[4] F. Wu and J. Ma, "The chaos dynamic of multiproduct Cournot duopoly game with managerial delegation," Discrete Dynamics in Nature and Society, vol. 2014, Article ID 206961, 10 pages, 2014.

[5] A. Matsumoto and Y. Nonaka, "Statistical dynamics in a chaotic Cournot model with complementary goods," Journal of Economic Behavior and Organization, vol. 61, no. 4, pp. 769-783, 2006.

[6] F. Tramontana, "Heterogeneous duopoly with isoelastic demand function," Economic Modelling, vol. 27, no. 1, pp. 350$357,2010$.

[7] F. Tramontana and A. E. A. Elsadany, "Heterogeneous triopoly game with isoelastic demand function," Nonlinear Dynamics, vol. 68, no. 1-2, pp. 187-193, 2012.

[8] H.-X. Yao, L. Shi, and H. Xi, "Analysis of triopoly game with isoelastic demand function and heterogeneous players," Discrete Dynamics in Nature and Society, vol. 2012, Article ID 280824, 16 pages, 2012.

[9] M. T. Yassen and H. N. Agiza, "Analysis of a duopoly game with delayed bounded rationality," Applied Mathematics and Computation, vol. 138, no. 2-3, pp. 387-402, 2003.
[10] F. Chen, J. H. Ma, and X. Q. Chen, "The study of dynamic process of the triopoly games in chinese $3 \mathrm{G}$ telecommunication market," Chaos, Solitons \& Fractals, vol. 42, no. 3, pp. 1542-1551, 2009.

[11] Y. Guo and J. Ma, "Research on game model and complexity of retailer collecting and selling in closed-loop supply chain," Applied Mathematical Modelling, vol. 37, no. 7, pp. 5047-5058, 2013.

[12] T. Li, J. Ma, and L. Sun, "Complexity uncertainty analysis of dynamic in a dual-channel energy supply chain model with heterogeneous retailers," Mathematical Problems in Engineering, vol. 2015, Article ID 562158, 10 pages, 2015.

[13] J. Ma and Z. Guo, "Research on the complex dynamic characteristics and RLS estimation's influence based on price and service game," Mathematical Problems in Engineering, vol. 2015, Article ID 302506, 13 pages, 2015.

[14] J. Ma and Q. Li, "The complex dynamics of Bertrand-Stackelberg pricing models in a risk-averse supply chain," Discrete Dynamics in Nature and Society, vol. 2014, Article ID 749769, 14 pages, 2014.

[15] L. Sun and J. Ma, "Study and simulation on discrete dynamics of Bertrand triopoly team-game," Mathematical Problems in Engineering, vol. 2015, Article ID 960380, 12 pages, 2015.

[16] Z. Sun and J. Ma, "Complexity of triopoly price game in Chinese cold rolled steel market," Nonlinear Dynamics, vol. 67, no. 3, pp. 2001-2008, 2012.

[17] A. K. Naimzada and F. Tramontana, "Dynamic properties of a Cournot-Bertrand duopoly game with differentiated products," Economic Modelling, vol. 29, no. 4, pp. 1436-1439, 2012.

[18] J. Ma and X. Pu, "The research on Cournot-Bertrand duopoly model with heterogeneous goods and its complex characteristics," Nonlinear Dynamics, vol. 72, no. 4, pp. 895-903, 2013.

[19] H. Wang and J. Ma, "Complexity analysis of a CournotBertrand duopoly game model with limited information," Discrete Dynamics in Nature and Society, vol. 2013, Article ID 287371, 6 pages, 2013. 


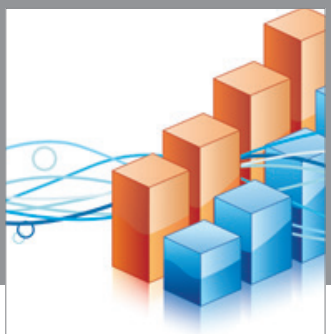

Advances in

Operations Research

vatem alat4

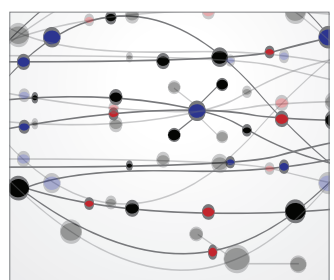

\section{The Scientific} World Journal
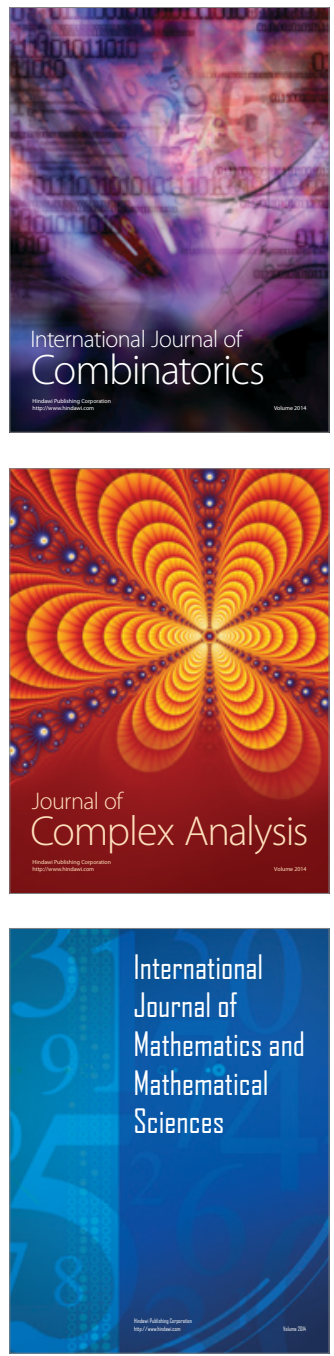
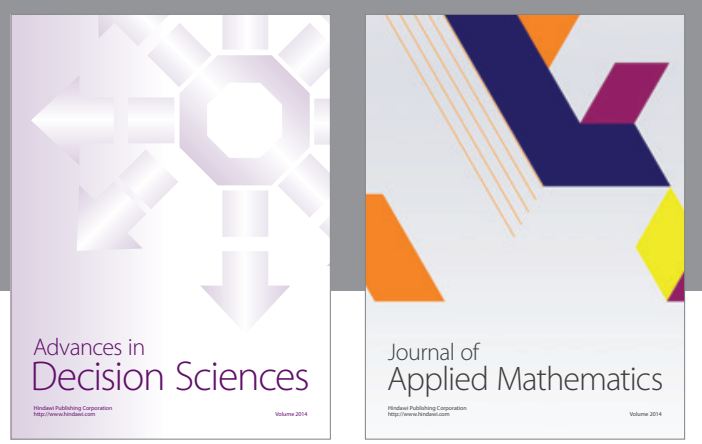

Algebra

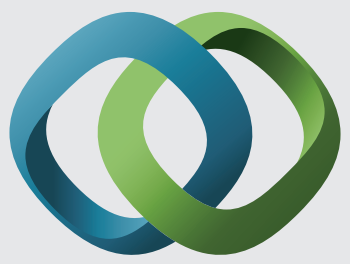

\section{Hindawi}

Submit your manuscripts at

http://www.hindawi.com
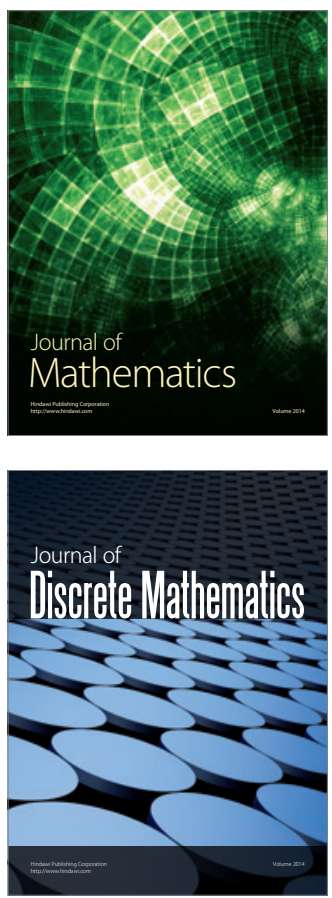

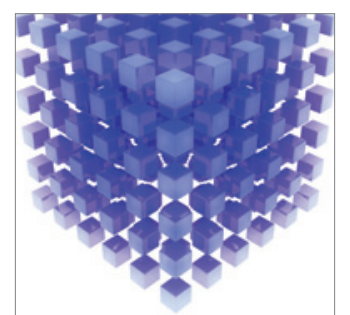

Mathematical Problems in Engineering
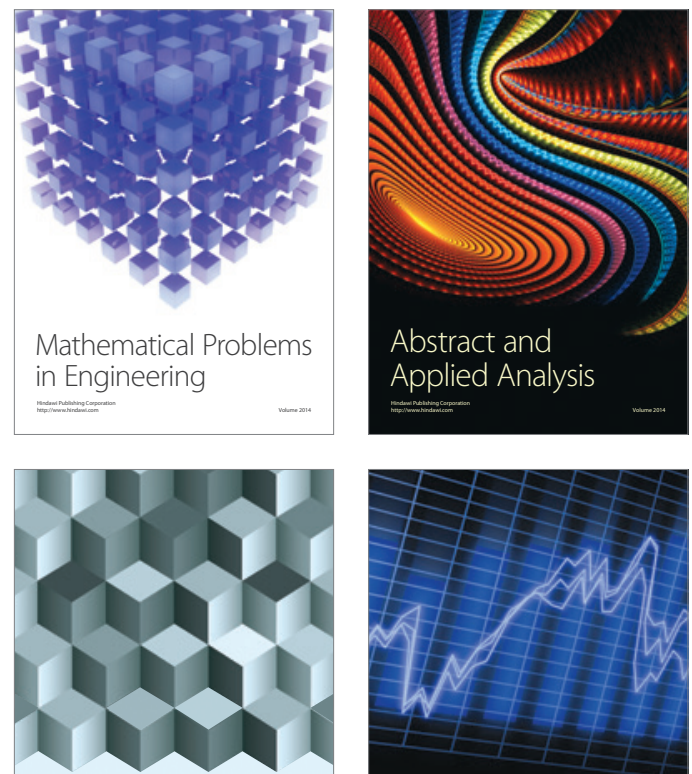

Journal of

Function Spaces

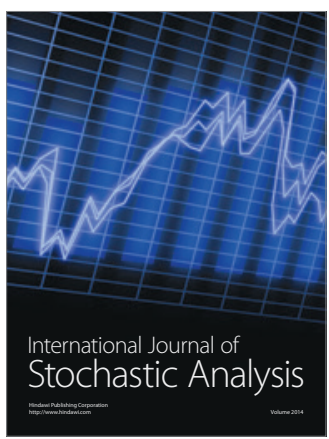

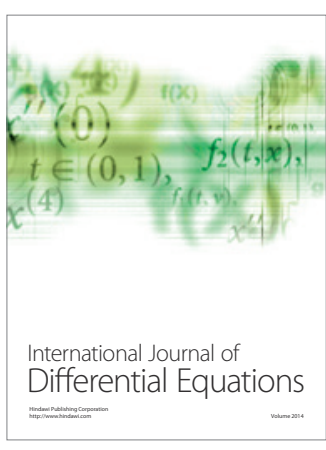
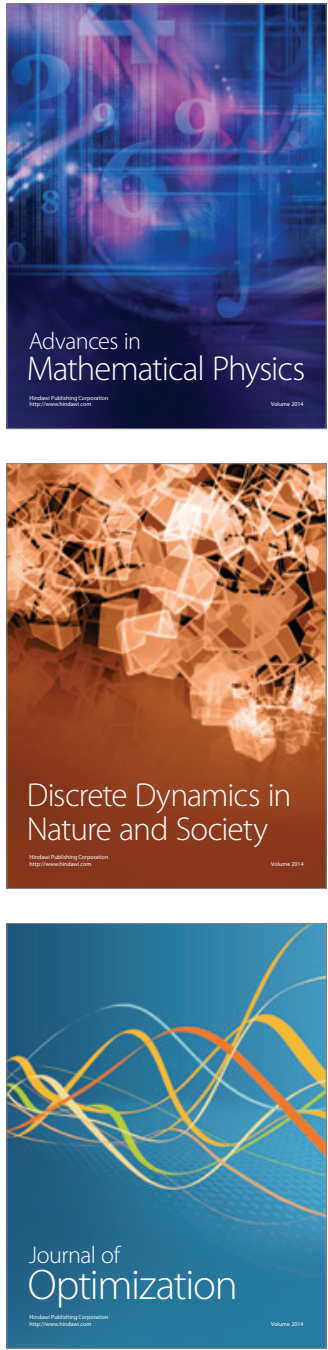